\title{
Toenail trace element status and risk of Barrett's oesophagus and oesophageal adenocarcinoma: results from the FINBAR study
}

\author{
Michael A. O'Rorke ${ }^{1}$, Marie M. Cantwell ${ }^{1}$, Christian C. Abnet ${ }^{2}$, John D. Brockman ${ }^{3}$, and \\ Liam J. Murray ${ }^{1}$ on behalf of the FINBAR Study Group \\ ${ }^{1}$ Cancer Epidemiology and Health Services Research Group, Centre for Public Health, Queens \\ University Belfast, Institute of Clinical Sciences Block B, RVH Site, Grosvenor Road, Belfast \\ BT12 6BA, UK \\ ${ }^{2}$ Nutritional Epidemiology Branch, Division of Cancer Epidemiology and Genetics, National \\ Cancer Institute, Rockville, MD, USA \\ ${ }^{3}$ Research Reactor Centre, University of Missouri-Columbia, 1513 Research Park Drive, \\ Columbia, MO 65211, USA
}

\begin{abstract}
Trace elements have been cited as both inhibitory and causative agents of cancer but importantly exposure to them is potentially modifiable. This study aimed to examine toenail trace element status and risk of Barrett's oesophagus (BO) and oesophageal adenocarcinoma (OAC). Toenail clippings from each hallux were obtained from 638 participants of the FINBAR study (Factors Influencing the Barrett's Adenocarcinoma Relationship) comprising 221 healthy controls, 98 reflux oesophagitis, $182 \mathrm{BO}$ and $137 \mathrm{OAC}$ cases. The concentrations of eight toenail trace elements were determined using Instrumental Neutron Activation Analysis. Using multivariable adjusted logistic regression analysis, odds ratios (OR) and 95\% CIs were calculated within tertiles of trace element concentrations. A two-fold increased risk of $\mathrm{BO}$ was observed, but not OAC, amongst individuals in the highest tertile of toenail zinc status OR 2.21 (95\% CI 1.11-4.40). A higher toenail selenium status was not associated with risk of OAC OR 0.94 (95\% CI 0.44-2.04) or BO OR 0.89 (95\% CI 0.37-2.12). A borderline significant increased risk of BO was detected with a higher toenail cobalt concentration, OR 1.97 (95\% CI 1.01-3.85). No association was found between toenail levels of chromium, cerium, mercury and OAC or BO risk. This is the first casecontrol study to investigate a variety of trace elements in relation to OAC and $\mathrm{BO}$ risk. Despite antioxidant and proapoptotic properties, no associations were found with selenium. Higher concentrations of toenail zinc and cobalt were associated with an increased BO risk, but not OAC. These findings need confirmation in prospective analysis.
\end{abstract}

\section{Keywords}

trace elements; Barrett's oesophagus; oesophageal adenocarcinoma; selenium; case-control study

Corresponding Author: Dr Michael O’Rorke, Centre for Public Health, Queen's University Belfast, ICS-B Building, RVH Site, Grosvenor Rd, Belfast, BT12 6BA, Northern Ireland. Tel: +44(0) 2890632219 |Fax: +44 (0) 2890235900 m.ororke@ qub.ac.uk. Conflicts of Interest: The authors declare that they have no conflict of interest 


\section{Introduction}

In recent decades oesophageal adenocarcinoma (OAC) has had the fastest increasing incidence of any malignancy in the developed world, particularly amongst white men in the USA $^{1}$ and Europe ${ }^{2}$; a changing epidemiology which has not been explained by misclassification with gastric cardia adenocarcinoma (GCA) ${ }^{3}$, nor improved diagnostic techniques, as trends differ between sexes ${ }^{4}$. In line with the rising incidence of OAC, there appears to have been a concomitant 'true' increase in the incidence of Barrett's Oesophagus (BO) ${ }^{5,6}$; a metaplastic pre-cursor state thought to be acquired through chronic exposure to caustic reflux as a consequence of Gastro Oesophageal Reflux Disease (GORD). 5-year survival from OAC has been reported to be as low as $8 \%$ in both sexes in the $\mathrm{UK}^{7}$ and less than $15 \%$ in most populations ${ }^{8}$; therefore research into modifiable risk factors for the prevention of this cancer are pivotal.

The role of dietary components in the pathogenesis of $\mathrm{OAC}$ and $\mathrm{BO}$ remains elusive; however epidemiological research between trace elements and cancer risk is growing ${ }^{9}$. Some trace elements are micronutrients that are present in the human body in minute quantities, several of which are essential for a variety of metabolic processes including iron, zinc, cobalt, chromium and selenium ${ }^{10}$. However exposure to some trace elements, such as mercury, can be detrimental to health. Trace elements readily bind to the fibrous proteins of hard keratin in toenails and given their slow growth, have been shown to be a reliable biomarker for trace element status ${ }^{11}$; typically reflecting past year exposure ${ }^{12}$. Moreover, in populations which routinely wear socks/shoes they are subjected to less external contamination than fingernails or hair, can be collected non-invasively, and are easier to transport and store ${ }^{13}$.

Selenium (Se) in particular has been looked upon as a potentially key anti-carcinogenic trace element, given its function as a cofactor of the glutathione peroxidase (GPx) family of enzymes, each with the biological role of protecting against oxidative stress; furthermore various Se compounds have been shown to act as antiproliferative and proapoptotic agents ${ }^{14}$ and have been attributed with antiviral and anticarcinogenic properties ${ }^{15}$. To date only two studies have examined toenail Se status in relation to risk of OAC and BO ${ }^{16,17}$, the principal findings of which have indicated no association with OAC or BO risk. Zinc $(\mathrm{Zn})$, a cofactor of over 300 catalytically active metalloenzymes ${ }^{18}$, plays a crucial role in the regulation, transcription, and replication of DNA ${ }^{19}$ and so like Se, is thought to have both antioxidant and proapoptotic properties ${ }^{18}$ which may inhibit OAC carcinogenesis. Cobalt (Co), (vitamin B12/cobalamin), is an essential cofactor in the methionine synthase reaction which is integrally involved in DNA biosynthesis, cell division, erythropoiesis and peripheral nerve myelination ${ }^{20}$, and so may play a role in cancer development. Pharmacologically, cerium (Ce) exerts diverse biological effects given its resemblance to calcium. Although the mechanisms of action remain unclear, Ce has been investigated in vitro for its anti-proliferative and antioxidant properties ${ }^{21,22}$. Other elements have been identified as potential causative agents of cancer, for example, hexavalent chromium $(\mathrm{Cr})$ (VI) can be mutagenic when inhaled ${ }^{23}$, however findings from a meta-analysis examining occupational exposure and cancers of the gastrointestinal tract have been inconclusive ${ }^{24}$. Similarly, despite the classification of mercury $(\mathrm{Hg})$ as a potential human carcinogen, there is no robust evidence affirming its role in the aetiology of human cancers ${ }^{25}$.

The aim of the present study was to therefore investigate the association between the states of several toenail trace elements including: $\mathrm{Se}, \mathrm{Zn}, \mathrm{Co}, \mathrm{Cr}, \mathrm{Hg}, \mathrm{Ce}$ and risk of OAC and $\mathrm{BO}$, using data from an all-Ireland case-control study, the FINBAR study (Factors INfluencing the Barrett's Adenocarcinoma Relationship study). 


\section{Materials and methods}

\section{Study design}

A detailed description of the FINBAR study, its participation fractions and case exclusions have been published elsewhere ${ }^{26}$; briefly this was an all-Ireland case-control study recruiting 227 patients with OAC (131 oesophageal, 92 junctional and 4 unclassified), 224 long segment BO and 260 population based controls from March 2002 through to December 2004. Response rates in FINBAR were $74.2 \%, 82.4 \%$ and $41.8 \%$ amongst OAC, BO and population controls respectively.

Patients aged $\$ 85$ years of age with a histological diagnosis of adenocarcinoma of the oesophagus (excluding in situ cancers) formed the OAC group. Eligible BO patients were those with $\geq 3 \mathrm{~cm}$ of typical Barrett's mucosa at endoscopy or in which biopsy evidenced the presence of specialised intestinal metaplasia; patients with dysplasia on histological inspection were excluded. Population controls were aged between 35-84 years with no prior history of oesophageal/gastrointestinal malignancy or known diagnosis of $\mathrm{BO}$ and were selected at random from general practitioner lists throughout Northern Ireland and from four general practices (two urban and two rural) in the Dublin and Cork city areas. All control patients were frequency matched to the cases within 5-year age bands and sex strata.

In Northern Ireland ethical committee approval was obtained from the Queen's University Belfast research ethics committee. In the Republic of Ireland consent was obtained from the clinical research ethics committee of the Cork teaching hospitals and the research ethics committee board of St. James Hospital, Dublin.

\section{Exposure assessment}

All structured Interviews were computerised and conducted by trained researchers. A brief medical history was taken from all subjects and information pertaining to medication usage, medical history, occupation, education and alcohol/smoking history was collected. Anthropometric measurements such as height, weight and waist and hip circumference were taken at the time of consultation. BMI five years prior to interview was assessed by dividing self reported weight $(\mathrm{kg})$ by height $\left(\mathrm{m}^{2}\right)$. Dietary intakes were assessed using a semi quantitative food frequency questionnaire; this was a modified version of that used in the European Prospective Investigation into Cancer and nutrition (EPIC) ${ }^{27}$.

\section{Toenail collection and Laboratory analysis}

Toenail clippings from each hallux were obtained from 638/941 (67.8\%) participants comprising: 221/260 (85\%) controls, 182/224 BO (81.3\%) and 137/227 OAC (60.4\%). A further 98/230 (42.6\%) toenail specimens were collected from a concurrent oesophagitis study in Northern Ireland, however given the low proportion of toenail specimens available from these reflux oesophagitis cases, their data wasn't utilised and was excluded from all subsequent analyses. All toenail specimens were placed in labelled re-sealable plastic pouches and stored at room temperature. In September 2008 these toenail samples were received bystaff (JB) at the University of Missouri Research Reactor (MURR, Columbia MO USA) for analysis wherein the concentrations of eight elements: $\mathrm{Se}$, iron (Fe), $\mathrm{Hg}, \mathrm{Zn}$, $\mathrm{Co}, \mathrm{Cr}$, scandium ( $\mathrm{Sc}$ ) and $\mathrm{Ce}$ were determined by Instrumental Neutron Activation Analysis (INAA) using methods which have been described in detail elsewhere ${ }^{12}$. It should be noted that toenail concentrations of Sc are not reported herein as this was used as a control element to account for sample contamination from chemicals or glassware prior to irradiation ${ }^{28}$. Although toenail Fe concentrations were determined in INAA, they have been published elsewhere with other iron data in relation to $\mathrm{BO}$ and OAC risk ${ }^{29}$. 
To minimise systematic differences that may have arisen in the way specimens were handled, case and control specimens were analysed in a random order together in batches of 100 by laboratory staff that were blinded to their case-control status. All toenail clippings were thoroughly washed with deionised water and $10 \%$ nitric acid using a sonicator, prior to being freeze dried and placed in pre-cleaned high density polyethylene vials. For $\mathrm{Se}$ determination, specimens were irradiated with neutrons and transferred to a high-resolution gamma-ray spectrometer where the gamma-ray from the decay of ${ }^{77 \mathrm{~m}} \mathrm{Se}$ was quantified and Se concentrations determined. Samples were co-analysed with NIST SRM 1577b (Bovine liver) quality controls which have a certified Se value of $1.1 \pm 0.1 \mu \mathrm{g} / \mathrm{g}$. The average (mean $\pm \mathrm{SD}$ ) Se value across the samples was $1.07 \pm 0.3 \mu \mathrm{g} / \mathrm{g}$ which agreed well with the certified controls. Of the 638 samples available for Se analysis, 236 (37\%) had sufficient mass to run the analysis with a duplicate sample to check for sample homogeneity and reproducibility; 3 samples were found to have inconsistent Se concentrations and were subsequently excluded from Se analysis. For further multi-element determinations the toenail samples were irradiated for 50 hours, allowed to decay for 6-10 days and similarly quantified by a gamma-ray spectrometer. 73/638 samples were of sufficient mass to allow duplicates to be primed and analysed. Observed and accepted mean values between the co-analysed toenail samples and quality control materials NIST SRM 1577b (bovine liver), NIST SRM 1571 (orchid leaves) and NCS DC 73347 (human hair) were satisfactorily comparable. Toenail samples from two subjects (1 BO and 1 control) were mixed together during multi-element determination and were excluded from subsequent analyses. Additionally, 41/638 toenail samples analysed had a very low mass $(<0.01 \mathrm{~g})$ and were excluded from all subsequent analyses.

\section{Statistical analysis}

Differences in demographic characteristics between cases and controls were examined using a ttest for continuous variables and Chi squared test for categorical data (all tests were twotailed and $a=0.05$ ). A natural logarithmic (loge) transformation of all toenail element concentrations was undertaken prior to analysis to approximate a normal distribution. Multivariate logistic regression analysis was then used to investigate the association between tertiles of toenail trace element concentrations and risk of OAC and BO vs. controls to attain Odds Ratios (ORs) and 95\% confidence intervals (95\% CIs). Using a parsimonious backwards elimination approach, the ORs of confounders identified as statistically significantly affecting an association (a $\$ \mathbf{S} .05 \%$ ) were entered into the final models. A range of available confounders were considered including: BMI five years prior to the date of interview $\left(\mathrm{kg} / \mathrm{m}^{2}\right)$, alcohol intake ( $\mathrm{g} /$ day), total energy intake (Kcal), manual/non manual work, gastro oesophageal reflux symptoms i.e.: symptoms of heartburn or acid reflux experienced at least once weekly five years prior to the interview date (ever/never), hpylori infection seropositivity (+ve/-ve), Non-Steroidal Anti-Inflammatory Drug use at least once weekly for $\zeta$ mths or more (ever/never), education (yrs), location (Republic of Ireland/ Northern Ireland), vitamin C intake (mg/day). Although data on waist to hip ratio was available, there was no material difference to the effect estimates if this was substituted for BMI in multivariate models. Where data was available, adjustment for other metals which could affect the uptake, transport, metabolism and physiological activity of the element under investigation (antagonistic elements) was undertaken i.e.: In the analysis of Se, zinc and copper were initially included in the multivariate model. Age (yrs), gender and smoking status (current, former, never) were retained in the models, irrespective of significance, given their potential moderating effects on toenail trace element concentrations ${ }^{13}, 30,31$. Tertile cut-points were derived using toenail concentrations from the controls as the reference population. In the analysis of $\mathrm{Ce}$ and $\mathrm{Cr}, 67.1 \%$ (345/514) and 75.7\% (389/514) of subjects respectively, had a toenail concentration that was at or below the Limit of Detection (LOD). To minimise any resultant bias ${ }^{32}$, analysis was confined to just two categories of 
above LOD ( $>0.015$ and $>0.4 \mu \mathrm{g} / \mathrm{g}$ for $\mathrm{Ce}$ and Cr respectively) and at or below the LOD ( $₫ 0.015$ and $₫) .4 \mu \mathrm{g} / \mathrm{g}$ for $\mathrm{Ce}$ and $\mathrm{Cr}$ respectively), ensuring that those individuals with the lowest trace element exposure were placed in the lowest category. Although unplanned, subgroup explorations (limited to the analysis of Se) were undertaken to enable comparison with the only other studies which have investigated toenail Se status and OAC and BO risk ${ }^{16,17}$. Upon post-hoc subgroup analysis, resultant regression models failed to achieve convergence because the number of OAC and $\mathrm{BO}$ cases in relation to explanatory variables was small ${ }^{33}$. To test for linear trends across the trace element tertiles, the element was entered as a continuous variable in the regression models. Tests for interaction were performed using the log-likelihood ratio statistic. All statistical analyses were conducted using STATA version 11.0 (Stata Corp LP, College Station, Texas).

\section{RESULTS}

In comparison to individuals providing a toenail specimen, a higher proportion of those that did not were recruited from the Republic of Ireland and (amongst population controls only) had a high waist to hip ratio. There were no statistically significant differences between individuals who provided or did not provide a toenail specimen in terms of age, gender, smoking status, BMI or frequency of GOR symptoms (Suppl. Table 1).

The characteristics of cases and controls who returned a toenail sample are shown in Table 1. There were no significant differences between case and control groups by age or gender. OAC cases had a higher average BMI and a greater proportion were current smokers than population controls. BO cases had a significantly higher energy intake and both alcohol intake and years of education was significantly lower amongst $\mathrm{OAC}$ cases in comparison to population controls. Almost half of OAC cases (46\%) and over 70\% of BO cases reported experiencing GOR symptoms more frequently than controls (18\%), a difference which was significant. A higher proportion of controls had tested positive for h-pylori infection in comparison to either OAC or BO cases. Both $\mathrm{BO}$ and $\mathrm{OAC}$ cases had a lower mean toenail Se concentration than controls $\mathrm{p}=0.001$ and $\mathrm{P}=0.019$ respectively. Toenail concentrations of $\mathrm{Zn}$ were also observed to be significantly higher amongst $\mathrm{BO}$ cases than population controls $\mathrm{p}=0.017$. There were no other statistically significant differences in mean toenail trace element concentrations across the case groups (Table 2).

\section{Selenium \& Zinc}

In multivariate logistic regression analyses no association was observed between risk of OAC and BO comparing the lowest tertile of toenail Se to the highest, OR 0.94 (95\% CI $0.44-2.04$ ) and OR 0.89 (95\% CI 0.37-2.12) for OAC and BO cases respectively (Table 3). Confounders in the multivariate model that account most for the transition from a protective association observed in minimally adjusted models are GOR symptoms, $h$-pylori infection, smoking status, alcohol and years of education. In unplanned subgroup analysis those individuals in the highest tertile of toenail Se and who were current smokers had a twofold greater risk of OAC OR $2.83(95 \%$ CI 1.10-7.28; p interaction $=0.01)$. Conversely, although not significant, higher toenail Se status was associated with an increased risk of BO amongst never smokers (Table 4). In multivariable models no association was observed between those cases in the highest tertile of toenail $\mathrm{Zn}$ concentrations and risk of OAC OR 0.92 (95\% CI 0.50-1.69), however, a consistent significantly higher risk of BO was detected in univaraite and multivariate models OR 2.21 (95\% CI 1.11-4.40) (Table 3).

\section{Mercury \& Cobalt}

Multivariable analysis showed no statistically significant association between tertiles of toenail Hg and risk of OAC OR 0.76 (95\% CI 0.36-1.62) or BO OR 0.72 (95\% CI 0.33- 
1.57) (Table 3). A borderline significant increased risk of BO OR 1.97 (95\% CI 1.01-3.85) was observed with higher toenail concentration of Co in relation to population controls. Although insignificant, a weaker positive association was also observed amongst OAC cases OR 1.54 (95\% CI 0.84-2.85) (Table 3).

\section{Cerium \& Chromium}

In multivariable analysis there was no association between those individuals with a detectable toenail Ce concentration and risk of OAC OR 0.73 (95\% CI 0.36-1.47) or BO OR $1.53(95 \%$ CI $0.77,3.03)$ in comparison to individuals who had little or no exposure to this element (Table 3). Similar results were observed amongst the highest toenail $\mathrm{Cr}$ concentrations and risk of OAC OR 0.82 (95\% CI 0.39-1.73) and BO OR 1.21 (95\% CI 0.56-2.60) (Table 3).

\section{Discussion}

To the authors' knowledge this is the first case-control study to have investigated the association between a variety of toenail trace elements and OAC and BO risk. No association was found between higher toenail concentrations of Se and risk of BO or OAC. $\mathrm{BO}$ but not OAC, was positively associated with a higher toenail concentration of $\mathrm{Zn}$ and $\mathrm{Co}$. No associations were found between higher concentrations of toenail $\mathrm{Cr}, \mathrm{Ce}$ or $\mathrm{Hg}$ and either OAC or BO risk.

Two prior prospective investigations ${ }^{16,17}$, both conducted within the Netherlands Cohort Study, have examined toenail Se status in relation to OAC and BO risk respectively. In their first paper, Steevens et all found no clear association with higher toenail Se status and risk of OAC RR 0.76 (95\% CI 0.41-1.40); a finding affirmed in this case-control analysis. The authors reported a significant inverse association between toenail Se and OAC risk amongst never smokers RR 0.74 (95\% CI 0.64- 0.86), and although based on small numbers, amongst women RR 0.72 (95\% CI 0.61-0.84). It's conceivable that a high dietary intake of $\mathrm{Se}$ (and hence correlated higher toenail Se status) may counteract the negative oxidative damage induced by smoking, however in unplanned stratified analysis of Se and smoking status from the FINBAR study there was a significant two fold increased risk of OAC amongst current smokers and a non significant decreased risk amongst never smokers; perhaps reflecting the inability of Se to completely counteract the oxidative stress induced by smoking, especially as many of the anti-carcinogenic effects of Se are observed at supranutritional doses 34 .

In a subsequent examination Steevens et al ${ }^{17}$ found no evidence of an association between BO risk and toenail Se status RR 1.06 (95\% CI 0.71-1.57; p trend = 0.99), nor in subgroup analyses defined by sex, smoking status, BMI or antioxidant intake. Mean Se levels in the FINBAR study were $0.49 \mu \mathrm{g} / \mathrm{g}$ and $0.48 \mu \mathrm{g} / \mathrm{g}$ amongst OAC and BO cases respectively and $0.52 \mu \mathrm{g} / \mathrm{g}$ amongst population controls, the median toenail Se level in the Netherlands Cohort study was $0.55 \mu \mathrm{g} / \mathrm{g}$; concentrations which lie in the mid range of those reported elsewhere in Europe $(\mu \mathrm{g} / \mathrm{g})$ : 0.45 In Germany (Berlin), 0.57 in Scotland (Edinburgh) and 0.83 in Finland (Helsinki) ${ }^{35}$. Of note, one previous cross-sectional study has examined serum Se levels as a marker for neoplastic progression of $\mathrm{BO}^{36}$, finding that higher levels were associated with a reduced risk of high-grade dysplasia in patients with BO, OR 0.5 (95\% CI 0.3-0.9).

In the present study a higher toenail $\mathrm{Zn}$ concentration was associated with a twofold increased risk of BO; however no association was observed with OAC. Mean toenail $\mathrm{Zn}$ concentrations were $70.72,74.7$ and $70.11 \mu \mathrm{g} / \mathrm{g}$ amongst $\mathrm{OAC}$ and $\mathrm{BO}$ cases and population controls respectively. These levels appear to be lower in comparison to other levels in 
Europe $(\mu \mathrm{g} / \mathrm{g})$ : Berlin 108.3, Edinburgh 112.93, Helsinki 102.8, Malaga 102.9 and Moscow 103.8 37. There have been no further studies which have examined OAC or BO in relation to toenail $\mathrm{Zn}$ status. Notably however, toenail $\mathrm{Zn}$ has been shown to correlate well with dietary $\mathrm{Zn}$ intake, even in healthy populations with little $\mathrm{Zn}$ deficiency and high $\mathrm{Zn}$ supplementation rates ${ }^{38}$. Importantly, $\mathrm{Zn}$ metalloenzymes such as metallothionein, are powerful antioxidants and scavengers of hydroxyl radicals 39,40 and may therefore have associated anti-cancer effects. However, to date the nutritional contribution to BO and OAC is largely unknown ${ }^{41}$; a previous analysis of the dietary intake of $\mathrm{Zn}$ from the FINBAR study ${ }^{42}$ found no association between higher intakes and the risk of $\mathrm{BO}$ or OAC. This incongruence with the present findings of an increased risk of $\mathrm{BO}$ may be due to the different dietary assessment methods utilised i.e.: the use of toenails as a biomarker of dietary $\mathrm{Zn}$ intake may avoid measurement errors incurred through self-reported dietary intakes on the food frequency questionnaires.

Interestingly, Abnet et a ${ }^{13}$ observed that individuals with oesophageal dysplasia (a precursor lesion to OSCC) had higher tissue $\mathrm{Zn}$ concentrations in their oesophageal tissue than those with no oesophageal dysplasia or OSCC. Although histologically disparate, this may lend support to the present study findings of higher $\mathrm{Zn}$ deposition in toenail tissue observed in the pre malignant lesion BO than either controls or patients with OAC. Similar findings have been observed in prostate cancer in which $\mathrm{Zn}$ levels in the malignant vs. normal prostate tissue are often $60-70 \%$ lower ${ }^{44,45}$. It would therefore be useful for prospective studies to further examine toenail $\mathrm{Zn}$ concentrations in relation to $\mathrm{BO}$ and $\mathrm{OAC}$ risk. No studies to date have examined the role of other toenail trace elements and OAC or $\mathrm{BO}$ risk for comparison with the present findings.

The principal strengths of the FINBAR study are its population based design, rapid case ascertainment and stringent inclusion criteria for Barrett's oesophagus (specialised intestinal metaplasia, length $\geq 3 \mathrm{~cm}$ ). Additionally, it was possible to adjust for a range of potential confounders including $h$-pylori seropositivity and symptoms of GORD. However, both GORD and BMI were ascertained in the five year period prior to the interview date in cases and controls raising the potential for recall bias of these exposures. A high proportion of $\mathrm{BO}$ patients report having no reflux symptoms prior to diagnosis; consequently the overall prevalence of BO remains low ${ }^{46}$. Therefore the associations observed in the present study may have been attenuated by the absence of $\mathrm{BO}$ diagnosis in asymptomatic controls. Participation rates in FINBAR were $74.2 \%$ and $82.4 \%$ amongst OAC and BO cases respectively. Control response rates were much lower at $41.8 \%$, raising a potential issue with selection bias ${ }^{47}$. As published previously however ${ }^{26}$, controls were similar to the general population with regards to symptoms of GORD, mean weight and BMI. This suggests that respondents largely reflect (on important covariates) the population from which they were drawn. However, in the 2001 Northern Ireland health and social wellbeing survey $4823.6 \%$ of males (55 years or over) were current smokers, $53.1 \%$ former smokers and $23.3 \%$ never smokers. In the present study $83 \%$ of control respondents were male and $16 \%, 41 \%$ and $43 \%$ were current, former and never smokers respectively. Therefore the percentage of current smokers may be slightly underrepresented and the number of nonsmokers overrepresented in this study in comparison to the general population, leading to the potential overestimation of a positive association of cigarette smoking and OAC/BO, particularly in subgroup analyses of this exposure. There is no comparable population-based data on the average concentration of selected toenail trace elements in Northern Ireland/ Ireland. However, trace element concentrations for Se for example $(0.52 \mu \mathrm{g} / \mathrm{g})$, appear to be in line with similar control populations in the $\mathrm{UK}^{49}(0.59 \mu \mathrm{g} / \mathrm{g})$ and Europe ${ }^{17}(0.54 \mu \mathrm{g} / \mathrm{g})$.

The overall response rate for toenail collection was $67.8 \%$ and was highest amongst population controls ( $85 \%)$. Failure to return samples by post was the main reason for not 
having complete toenail specimens across the case groups studied; moreover of the $90 \mathrm{OAC}$ cases recruited as hospital inpatients, $76.7 \%$ had habitually clipped their toenails prior to admission, which was problematic for procurement of a nail sample. A further limitation of this case-control study is that the samples were collected post-diagnosis, making it impossible to distinguish if the exposure changed as a consequence of the disease process itself (reverse causation). For example, preclinical anorexia and weight loss in combination with individual-level factors such as age, gender, smoking status and alcohol consumption; as well as extraneous influences such as warmer weather (i.e.: the season in which the nails were cut) and toe length (proportional to nail bed growth), are known determinants of trace element deposition $13,30,31$. The imperfect measurement of smoking status in the present analysis may have been insufficient to remove its confounding effect, therefore residual confounding by smoking status and other unmeasured variables remains a possibility. As has been previously discussed, post-hoc subgroup explorations in this case-control study were limited to the analysis of Se for comparison with extant literature; however, a statistical issue which frequently arises upon tests for interactions is that of multiple testing, resulting in an uncontrolled type 1 error rate ${ }^{50}$.

In summary, too few studies have been conducted in this field to enable any robust conclusions to be drawn. Only one prospective study has examined toenail levels of Se in relation to $\mathrm{OAC}$ and $\mathrm{BO}$ risk; findings of this prospective study and the analysis from this case-control study have both shown inconclusive results. The presented subgroup analyses of Se should be interpreted with caution given that they were not pre specified and the small sample size involved increases the chances of a spurious finding. This study observed a twofold increase in risk of BO amongst individuals in the highest tertile of toenail $\mathrm{Zn}$; however no association was observed with OAC. Higher toenail concentrations of cobalt were associated with a borderline significant increased risk of BO but not OAC. Given the number of statistical tests performed, these findings may have occurred by chance; these associations should be confirmed in further prospective analyses.

\title{
Supplementary Material
}

Refer to Web version on PubMed Central for supplementary material.

\section{Acknowledgments}

\begin{abstract}
We appreciate the contributions made by the study participants and their families. We thank the clinicians who were contacted throughout the study period and their secretaries for administrative support. We acknowledge the contribution of Miss Siobhan Reynolds, Ms Majella Gallagher, Ms Carol Anderson and Mr Martin McAnaespie and Dr Damian McManus. Thanks to the Ulster Cancer Foundation, the Northern Ireland Cancer Registry and the National Cancer Registry Ireland for their support and involvement in the research. The FINBAR study group members include L.J. Murray (Queen's University Belfast), L.A. Anderson (Queen's University Belfast), B.T. Johnston (Belfast Health \& Social Care Trust), R.G.P. Watson (Belfast Health \& Social Care Trust), J. McGuigan (Belfast Health \& Social Care Trust), H.R. Ferguson (Belfast Health \& Social Care Trust), S.J. Murphy (Craigavon Area Hospital), J.V. Reynolds (St James' Hospital, Dublin) and H. Comber (National Cancer Registry of Ireland).

Financial support: The principal author's research is supported by the Centre for Health Improvement, Queen's University Belfast, Northern Ireland. The FINBAR study was funded by the Northern Ireland Research \& Development Office, the Health Research Board, Ireland, the Ulster Cancer Foundation and the Charitable Fund of the Royal Groups of Hospitals, Belfast.
\end{abstract}

\section{Abbreviations}

$\begin{array}{ll}\text { BO } & \text { Barrett's oesophagus } \\ \text { OAC } & \text { oesophageal adenocarcinoma }\end{array}$




$\begin{array}{ll}\text { GCA } & \text { gastric cardia adenocarcinoma } \\ \text { GORD } & \text { gastro oesophageal reflux disease } \\ \text { OSCC } & \text { oesophageal squamous cell carcinoma } \\ \text { GOR } & \text { gastro oesophageal reflux } \\ \text { BMI } & \text { body mass index } \\ \text { INAA } & \text { instrumental neutron activation analysis } \\ \text { Zn } & \text { zinc } \\ \text { Se } & \text { selenium } \\ \text { Co } & \text { cobalt } \\ \text { Ce } & \text { cerium } \\ \text { Cr } & \text { chromium } \\ \text { Hg } & \text { mercury } \\ \text { Fe } & \text { Iron } \\ \text { Sc } & \text { scandium } \\ \text { OR } & \text { odds ratio } \\ \text { CI } & \text { confidence interval }\end{array}$

\section{References}

1. Brown LM, Devesa SS, Chow WH. Incidence of adenocarcinoma of the esophagus among white Americans by sex, stage and age. J Natl Cancer Inst. 2008; 100:1184-7. [PubMed: 18695138]

2. Bosetti C, Levi F, Ferlay J, Garavello W, Lucchini F, Beruccio P, Negri E, La Vecchia C. Trends in oesophageal cancer incidence and mortality in Europe. Int J Cancer. 2008; 122:1118-29. [PubMed: 17990321]

3. Pohl H, Welch HG. The role of overdiagnosis and reclassification in the marked increase of esophageal adenocarcinoma incidence. J Natl Cancer Inst. 2005; 97:142-6. [PubMed: 15657344]

4. Cook MB, Chow WH, Devesa SS. Oesophageal cancer incidence in the United States by race, sex and histologic type, 1977-2005. Br J Cancer. 2009; 101:855-9. [PubMed: 19672254]

5. Post PN, Siersema PD, van Dekken H. Rising incidence of clinically evident Barretts esophagus in the Netherlands: a nation-wide registry of pathology reports. Scan J Gastroenterol. 2007; 42:17-22.

6. Coleman HG, Bhat S, Murray LJ, McManus D, Gavin AT, Johnston BT. Increasing incidence of Barrett's oesophagus: a population-based study. Eur J Epidemiol. 2011 (In press).

7. Berrino F. International agency for research on cancer and commision of the European communities survival of cancer patients in Europe: the EUROCARE-2 study. International Agency for Research on Cancer. 1999

8. Mitry E, Rachet B, Quinn MJ, Cooper N, Coleman MP. Survival for cancer of the oesophagus in England and Wales up to 2001. Br J Cancer. 2008; 99:1-3. [PubMed: 18506149]

9. Navarro Silvera A, Rohan TE. Trace elements and cancer risk: a review of the epidemiologic evidence. Cancer Causes Control. 2007; 18:7-27. [PubMed: 17186419]

10. Aggett PJ. Trace elements in human nutrition. j trop pediatr. 1980:43-5. [PubMed: 6999167]

11. He K. Trace elements in nails as biomarkers in clinical research. Eur J Clin Invest. 2011; 41:98102. [PubMed: 20813017]

12. Garland M, Morris SJ, Rosner BA, Stampfer MJ, Spate VL, Baskett CJ, Willett WC, Hunter DJ. Toenail trace element levels as biomarkers: reproducability over a 6-Year period. Cancer Epidemiol Biomark Prev. 1993; 2:493-7. 
13. Slotnick MJ, Nriagu JO. Validity of human nails as a biomarker of arsenic and selenium exposure: a review. Environ Res. 2006; 102:125-39. [PubMed: 16442520]

14. Rayman MP. Selenium in cancer prevention: a review of the evidence and mechanism of action. $P$ Nutr Soc. 2005; 64:527-42.

15. Schrauzer GN. Selenium and selenium -antagonistic elements in nutritional cancer prevention. Crit Rev Biotechnol. 2009; 29:10-7. [PubMed: 19514899]

16. Steevens J, van den Brandt PA, Goldbohm RA, Schouten LJ. Selenium status and the risk of esophageal and gastric cancer subtypes: the Netherlands cohort study. Gastroenterology. 2009; 138:1704-13. [PubMed: 20006613]

17. Steevens J, Schouten LJ, Driessen ALC, Huysentruyt CJR, Keulemans YCA, Goldbohm A, van den Brandt PA. Toenail selenium status and the risk of Barrett's esophagus: the Netherlands Cohort Study. Cancer Causes Control. 2010; 21:2259-68. [PubMed: 20936529]

18. Ho E. Zinc deficiency, DNA damage and cancer risk. J Nutr Biochem. 2004; 15:572-8. [PubMed: 15542347]

19. Prasad, AS. Zinc and gene expression. In: Prasad, AS., editor. Biochemistry of Zinc. New York: Plenum Press; 1993. p. 55-76.

20. FoodAgriculture Organisation of the United Nations \& World Health Organisation (FAO/WHO). Human vitamin \& mineral requirements: report of a joint FAO/WHO expert consultation. Food \& Nutrition Division Food and Agriculture Organisation of the united nations. 2001

21. Celardo I, Pedersen JZ, Traversa E, Ghibelli L. Pharmacological potential of cerium oxide nanoparticles. Nanoscale. 2011; 3:1411-20. [PubMed: 21369578]

22. Palizban AA, Sadeghi-Aliabadi H, Abdollahpour F. Effect of cerium lanthanide on Hela and MCF-7 cancer cell growth in the presence of transferrin. Res Pharm Sci. 2010; 5:119-25. [PubMed: 21589800]

23. Agency for Toxic Substances Disease Registry (ATSDR). Toxicological profile for Chromium. US Department of Health and Human Services, Public Health Service; 2008.

24. Gatto NM, Kelsh MA, Mai DH, Suh M, Proctor DM. Occupational exposure to hexavalent chromium and cancers of the gastrointestinal tract: a meta-analysis. Cancer Epidemiol. 2010; 34:388-99. [PubMed: 20430714]

25. Agency for Toxic Substances Disease Registry (ATSDR). Toxicological profile for Mercury. US Department of Health \& Social Services, Public Health Service; 1999.

26. Anderson LA, Johnston BT, Watson PR, Murphy SJ, Ferguson HR, Comber H, McGuigan J, Reynolds JV, Murray LJ. Nonsteroidal anti-inflamatory drugs and the esophageal inflammationmetaplasia-adenocarcinoma sequence. Cancer Res. 2006; 66:4975-82. [PubMed: 16651456]

27. Day N, Oakes S, Luben R, Khaw KT, Bingham S, Welch A, Wareham N. EPIC Norfolk: study design and characteristics of the cohort. European Prospective Investigation of Cancer. Br J Cancer. 1999; 80:95-103. [PubMed: 10466767]

28. Küppers G, Erdtmann G. Trace element determination in high-purity scandium by neutron activiation analysis and pre-irradiation matrix seperation. J Radioanal Nucl Chem. 1995; 189:18390.

29. O’Doherty MG, Abnet CC, Murray LJ, Woodside JV, Anderson LA, Brockman JD, Cantwell MM. Iron intake and markers of iron status and risk of Barrett's esophagus and esophageal adenocarcinoma. Cancer Causes Control. 2010; 21:2269-79. [PubMed: 20936528]

30. Fleckman, P. Basic science of the nail unit. In: Scher, RK.; Daniel, CR., editors. Nails: Therapy, Diagnosis, Surgeryed. Philadelphia: Saunders; 1997. p. 37-54.

31. Hunter DJ, Morris JS, Chute CG, Kushner GA, Colditz MJ, Stampfer FE, Speizer FE, Willett WC. Predictors of selenium concentration in human toenails. Am J Epidemiol. 1990; 132:114-22. [PubMed: 2356804]

32. Lubin JH, Colt JS, Camann D, Davis S, Cerhan JR, Severson RK, Bernstein L, Hartge P. Epidemiologic evaluation of measurement data in the presence of detection limits. Environ Health Persp. 2004; 112:1691-6.

33. Peduzzi P, Concato J, Kemper E, Holford TR, Feinstein AR. A simulation study of the number of events per variable in logistic regression analysis. J Clin Epidemiol. 1996; 49:1373-9. [PubMed: 8970487] 
34. Combs, GF., Jr; Lu, J. Selenium as a cancer preventive agent. In: Hatfield, DL.; Berry, MJ.; Gladyshev, VN., editors. Selenium. 2. Springer; US: 2006. p. 249-64.

35. Kardinaal AFM, Kok FJ, Kohlmeier L, Martin-Moreno JM, Ringstad J, Gomez-Aracena J, Mazaev VP, Thamm M, Martin BC, Aro A, Kark JD, Delgado-Rodriguez M, et al. Association between toenail selenium and risk of acute myocardial infarction in european men, the EURAMIC study. Am J Epidemiol. 1997; 145:373-9. [PubMed: 9054242]

36. Rudolph RE, Vaughan TL, Kristal AR, Blount PL, Levine DS, Galipeau PC, Prevo LJ, Sanchez CA, Rabinovitch PS, Reid BJ. Serum selenium levels in relation to markers of neoplastic progression among persons with Barrett's oesophagus. J Natl Cancer Inst. 2003; 95:750-7. [PubMed: 12759393]

37. Martin-Moreno JM, Gorgojo L, Riemersma RA, Gomez-Aracena J, Kark JD, Guillen J, Jimenez J, Ringstad JJ, Fernandez-Crehuet J, Bode P, Kok FJ. for the heavy metals and Myocardial Infarction Study Group. Myocardial infarction risk in relation to zinc concentration in toenails. Brit J Nutr. 2003; 89:673-8. [PubMed: 12720587]

38. Gonzalez A, Peters U, Lampe JW, Satia JA, Whitea E. Correlates of toenail zinc in a free-living US population. Ann Epidemiol. 2008; 18:74-7. [PubMed: 17923419]

39. Costello LC, Franklin RB, Tan M, Bagasra O. Zinc and prostate cancer: a critical scientific, medical and public interest issue (United States). Cancer Causes Control. 2005; 16:901-15. [PubMed: 16132800]

40. Zaichick V, Sviridova TV, Zaichick SV. Zinc in the human prostate gland: normal, hyperplastic and cancerous. Int Urol Nephrol. 1997; 29:565-74. [PubMed: 9413764]

41. World Cancer Research Fund/American Institute for Cancer Research. Food, nutrition, physical activity and the prevention of cancer: a global perspective. AICR; 2007.

42. Murphy SJ, Anderson LA, Ferguson HR, Johnston BT, Watson PR, McGuigan J, Comber H, Reynolds JV, Murray LJ, Cantwell MM. Dietary antioxidant and mineral intake in humans is associated with reduced risk of esophageal adenocarcinoma but not reflux esophagitis or Barrett's esophagus. J Nutr. 2010; 140:1757-63. [PubMed: 20702746]

43. Abnet CC, Lai B, Qiao YL, Vogt S, Luo X-M, Taylor PR, Dong Z-W, Mark SD, Dawsey SM. Zinc concentration in esophageal biopsy specimens measured by $\mathrm{X}$-ray fluorescence and esophageal cancer risk. J Natl Cancer Inst. 2005; 97:301-6. [PubMed: 15713965]

44. Wong PF, Abubakar S. Comparative transcriptional study of the effects of high intracellular zinc on prostate carcinoma cells. Oncol Rep. 2010; 23:1501-16. [PubMed: 20428803]

45. Cousins RJ. A role of zinc in the regulation of gene expression. Procc Nut Soc. 1998; 57:307-11.

46. Gerson LB, Shetler K, Triadafilopoulos G. Prevalence of Barrett's esophagus in asympomatic individuals. Gastroenterology. 2002; 123:461-7. [PubMed: 12145799]

47. Mezei G, Kheifets L. Selection bias and its implications for case-control studies: a case study of magnetic field exposure and childhood leukaemia. Int J Epidemiol. 2006; 35:397-406. [PubMed: 16303812]

48. Northern Ireland Statistics and Research Agency. Northern Ireland health and social well-being survey. Belfast. 2001

49. Allen NE, Morris JS, Ngwenyama RA, Key TJ. A case-control study of selenium in nails and prostate cancer risk in British men. Brit J Cancer. 2004; 90:1392-6. [PubMed: 15054461]

50. Cabral HJ. Multiple comparissons procedures. Circulation. 2008; 117:698-701. [PubMed: 18250280] 


\section{Novelty}

- This is the first case-control study to have investigated the association between a variety of toenail trace elements and $\mathrm{OAC}$ and $\mathrm{BO}$ risk.

- In support of the only other previous study, no protective associations were found with higher toenail selenium concentrations. Uniquely, this study also examined the association with several other trace elements and found that individuals with the highest exposure to zinc and cobalt had a higher risk of BO; however the same associations were not seen for OAC risk. 


\section{Impact}

- The anti proliferative and proapoptotic effects of selenium and zinc have spawned research into their potential chemopreventive role. As various trace elements may be both inhibitory and causative agents of cancer, understanding their role in cancer pathogenesis could lead to future preventative measures or treatments. 


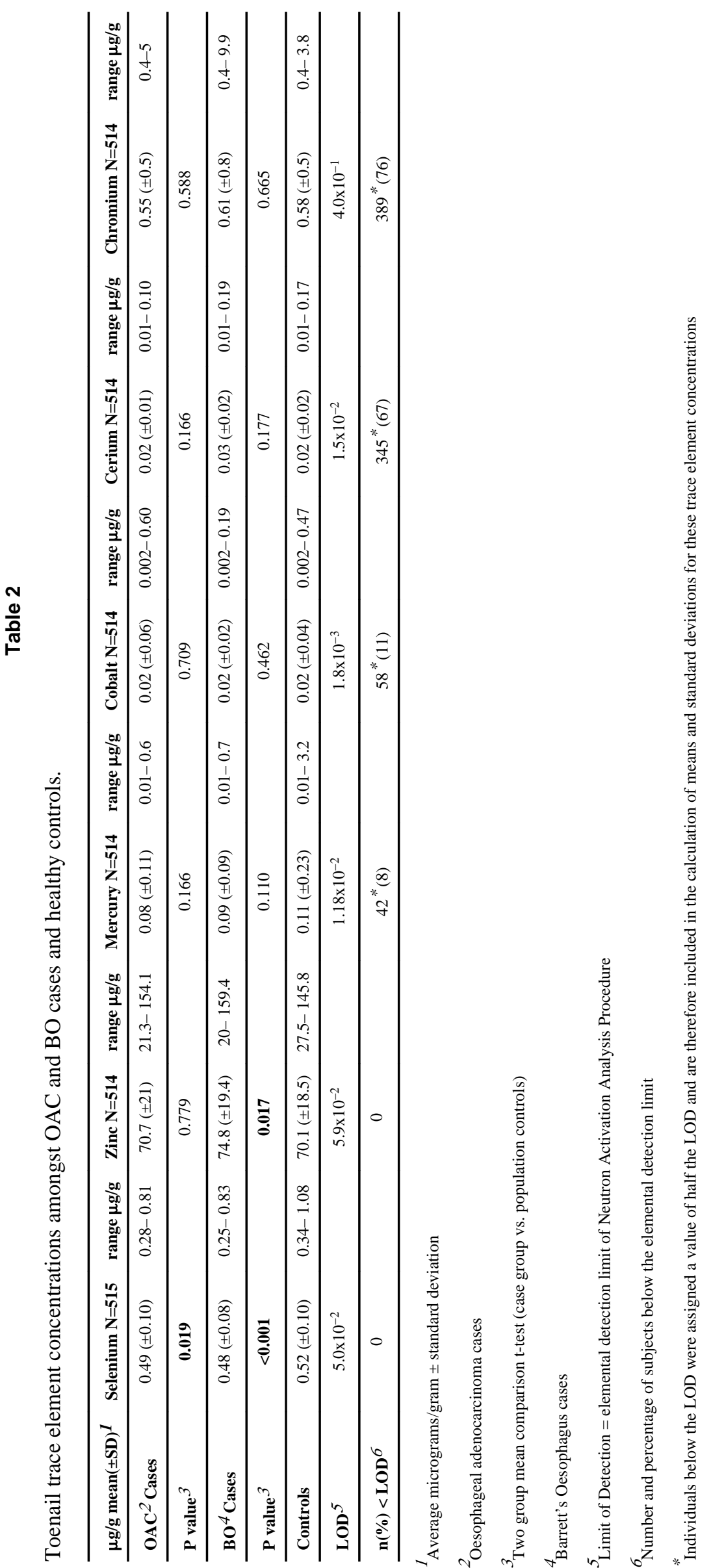




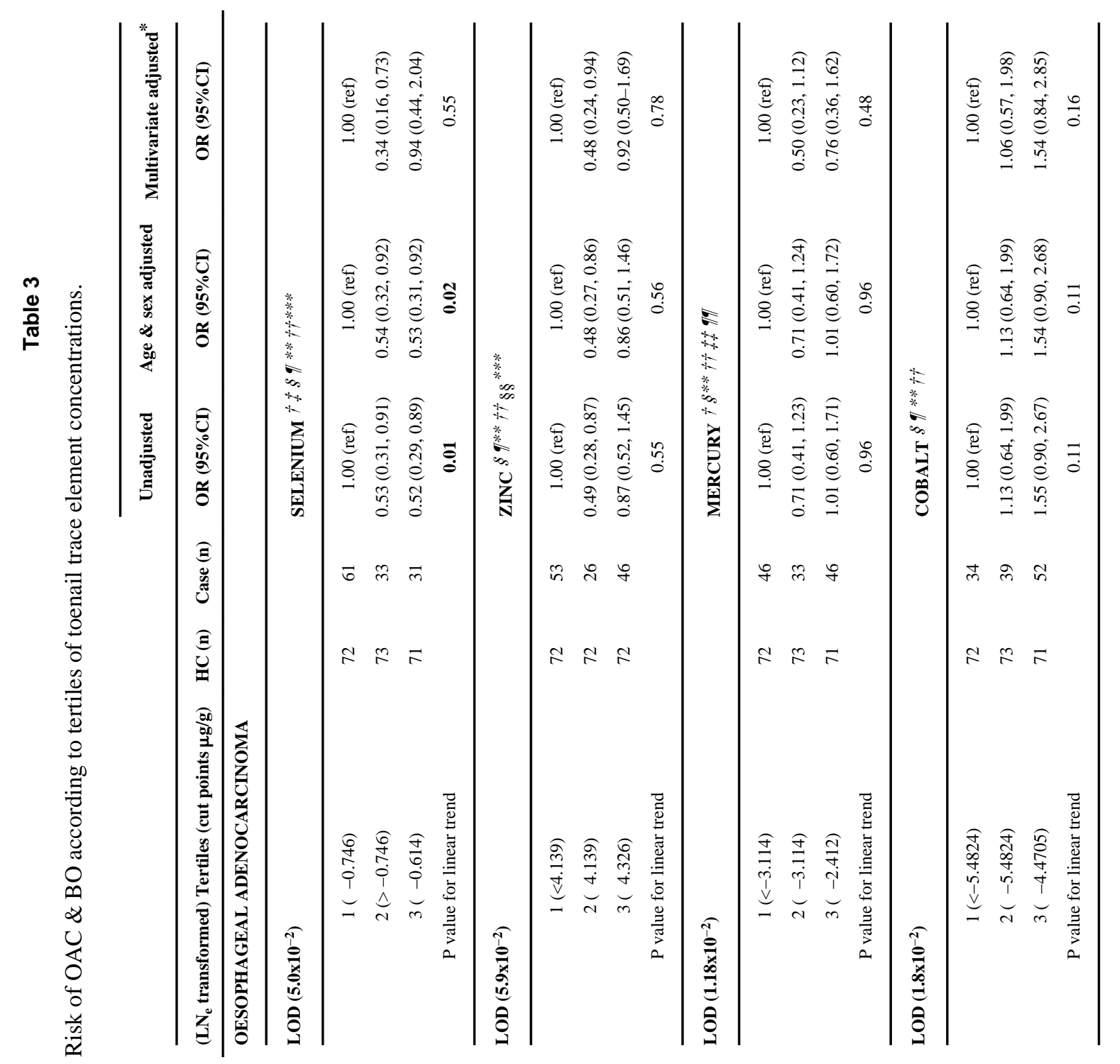




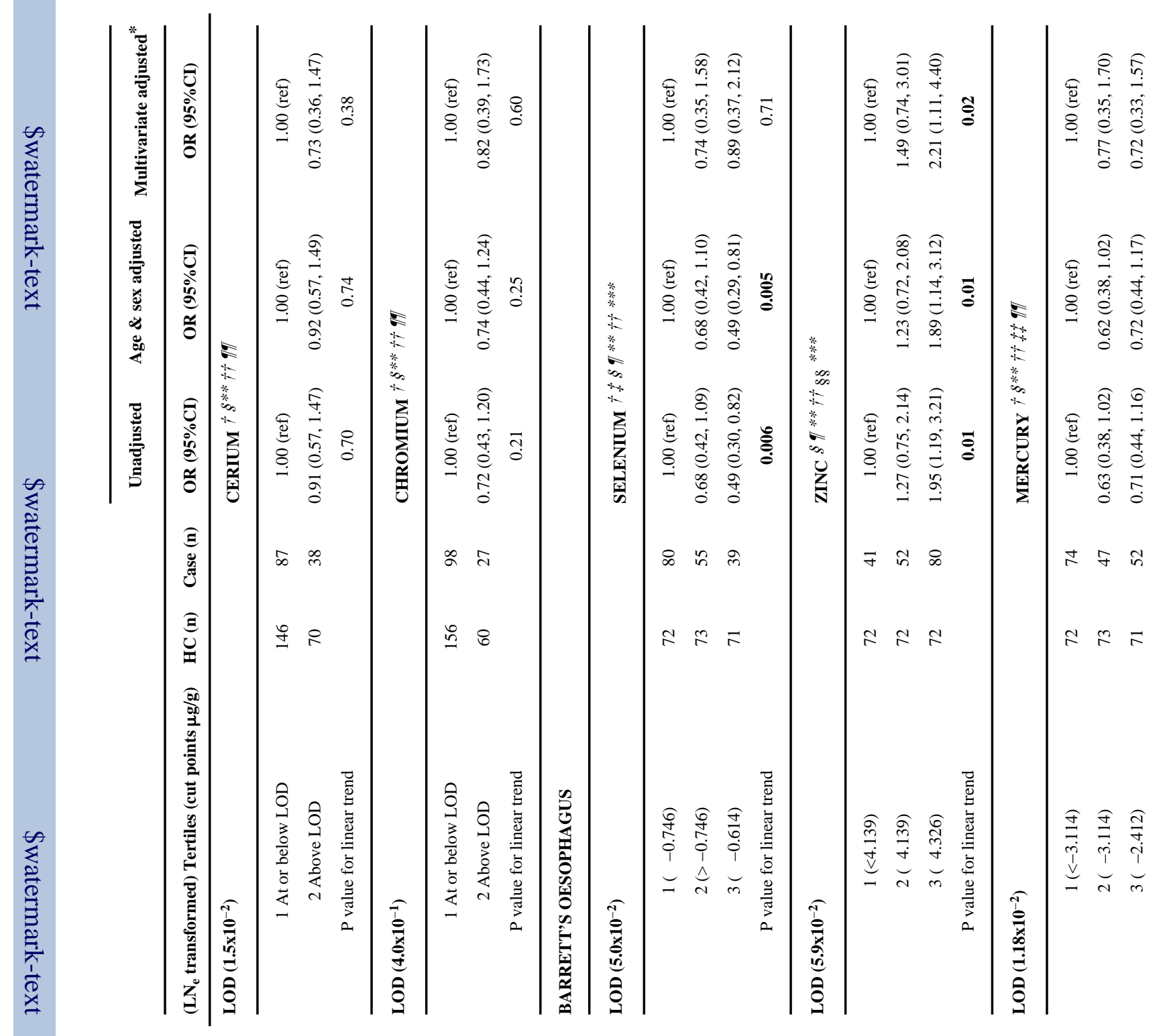




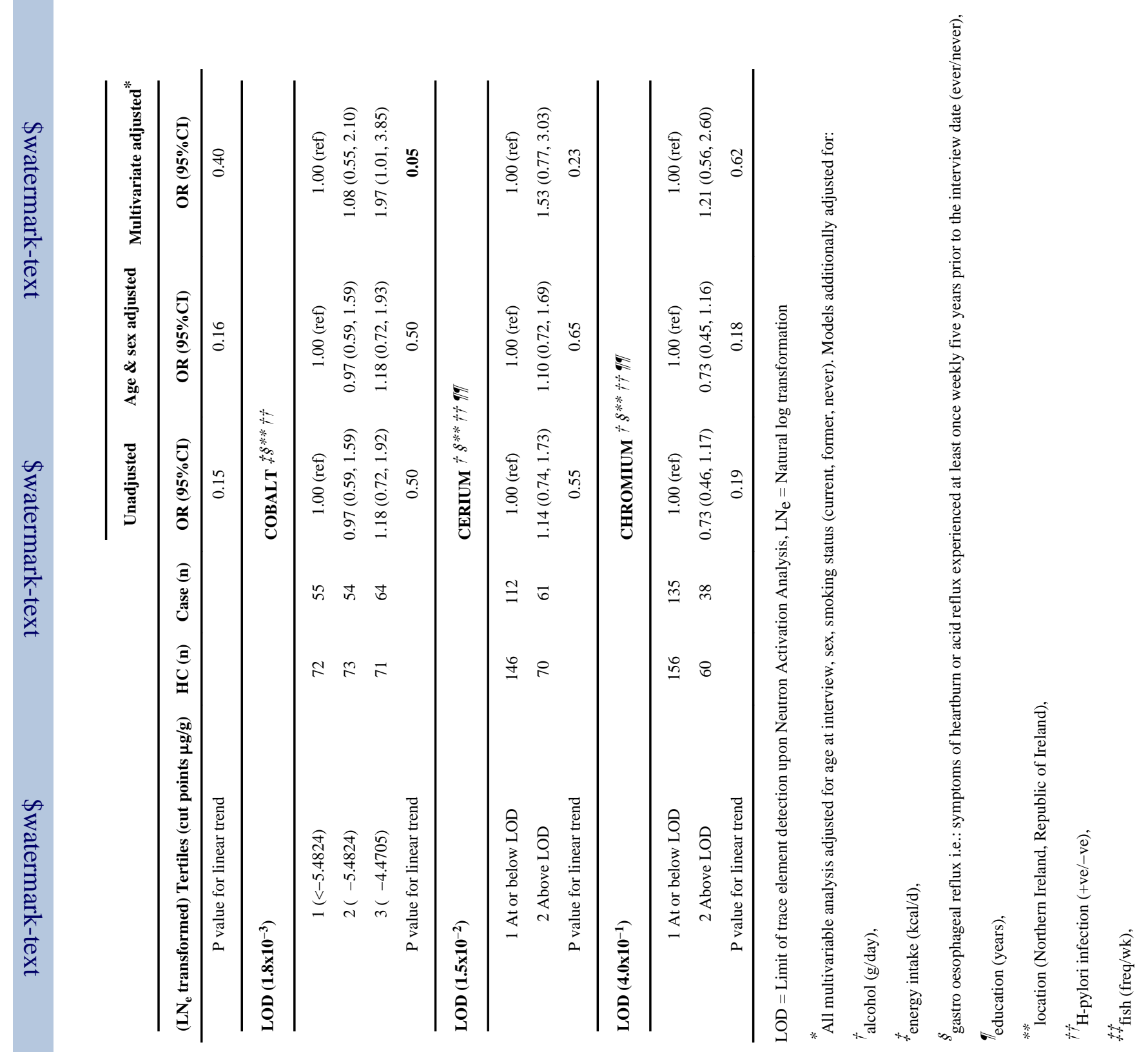




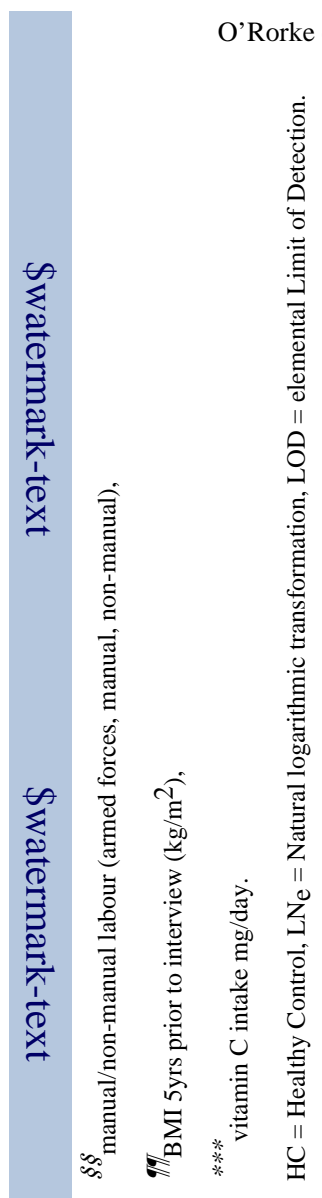

Page 19

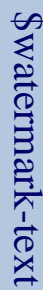

Int J Cancer: Author manuscript; available in PMC 2013 October 15. 


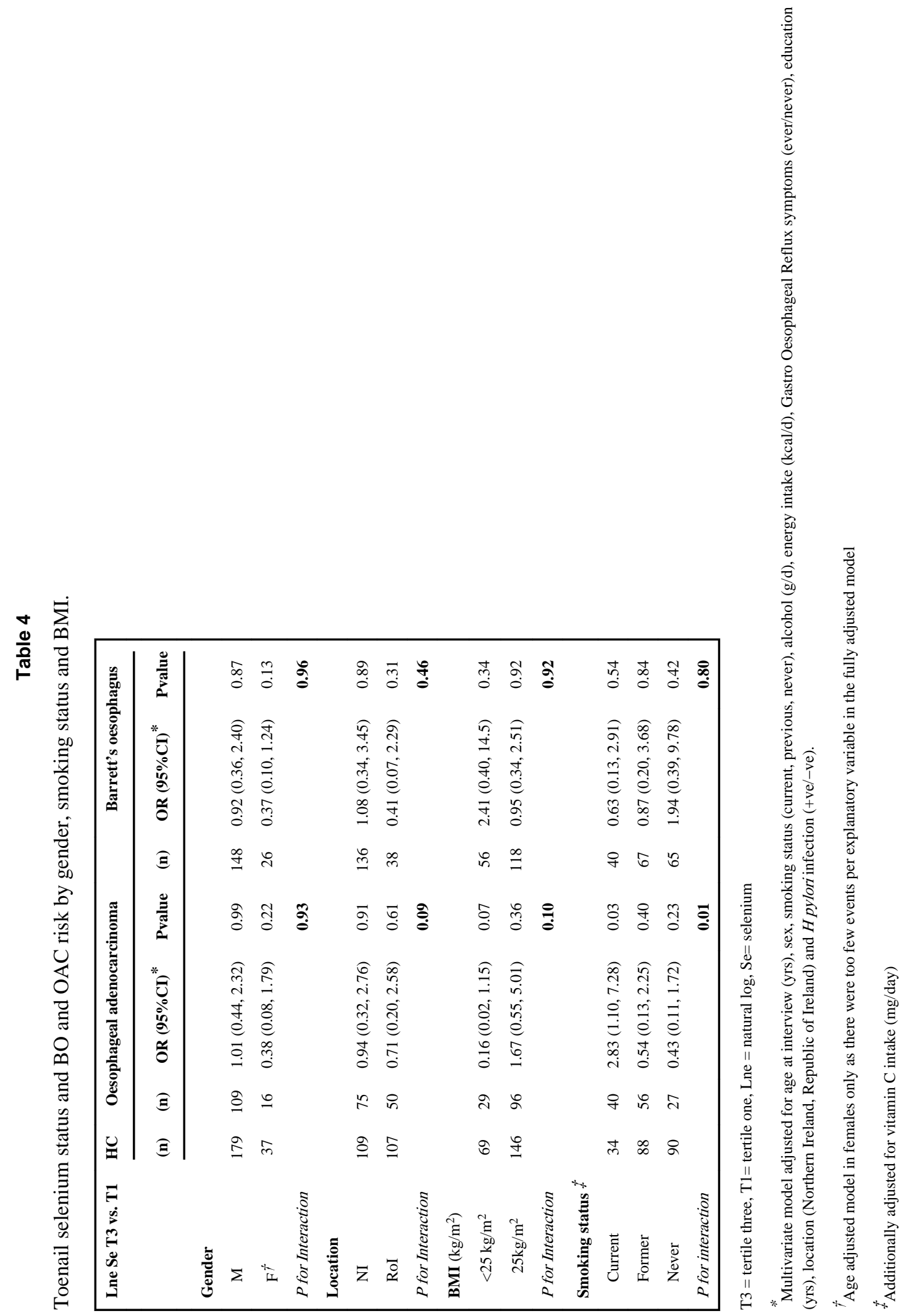

Int J Cancer: Author manuscript; available in PMC 2013 October 15. 